\title{
Edad, dinámica geomorfológica y tipología de barrancas en el sector norte del volcán Popocatépetl, México
}

\author{
Osvaldo Franco-Ramos, Lorenzo Vázquez-Selem, José Juan Zamorano-Orozco, \\ José Villanueva-Díaz
}

\begin{abstract}
Osvaldo Franco-Ramos
ofranco@igg.unam.mx

Departamento de Geografía Física, Instituto de Geografía, Universidad Nacional Autónoma de México, Ciudad Universitaria Coyoacán, 04510, México.
\end{abstract}

\section{Lorenzo Vázquez-Selem}

José Juan Zamorano-Orozco

Departamento de Geografía Física, Instituto de Geografía, Universidad Nacional Autónoma de México, Ciudad Universitaria Coyoacán, 04510, México.

\section{José Villanueva-Díaz}

INIFAP CENID RASPA, Gómez Palacio, Durango, Km 6.5 Margen Derecha del Canal Sacramento. Gómez Palacio, Dgo. 35140.

BOL. SOC. GEOL. MEX. 2017

VOL. 69 NO. 1

P. $1-19$

\section{RESUMEN}

En la presente investigación se estudió la edad y morfodinámica de barrancas originadas en depósitos piroclásticos del Pleistoceno tardío y Holoceno en la vertiente $\mathrm{N}$ del volcán Popocatépetl, con base en análisis estratigráficos, fechamientos ${ }^{14} \mathrm{C}$ y métodos dendrogeomorfológicos. Derivada de los resultados, se propone una tipología de barrancas en función de su origen, edad y dinámica geomorfológica. Las más antiguas y estables fueron excavadas en depósitos piroclásticos de hace $\sim 17000$ años cal. A.P., sus laderas se estabilizaron hace $\sim 6000$ años cal. A.P., fueron cubiertas por tefras de 5600 - 5900 y 1100 años cal. A.P., y han estado estables desde hace al menos 200 a. Las barrancas más jóvenes y activas fueron excavadas en depósitos piroclásticos de caída y flujo de la última erupción pliniana $(\sim 1100$ años cal. A.P.) durante las fases finales de dicha erupción o inmediatamente después de ésta; en ellos predominan condiciones de inestabilidad y han estado expuestas a eventos laháricos, como el caso de la barranca Huiloac.

Palabras clave: volcán Popocatépetl, barrancas, dendrogeomorfología, erosión post-eruptiva..

\section{ABSTRACT}

This study investigates the age and morphodynamics of ravines (barrancas) developed in late Pleistocene to Holocene pyroclastic deposits on the northern slope of Popocatépetl volcano by means of stratigraphic analyses, ${ }^{14} \mathrm{C}$ dating and dendrogeomorphologic methods. On this basis, we propose a typology for the ravines according to their origin, age and geomorphological dynamics. The oldest and most stable ravines formed in pyroclastic deposits emplaced at $\sim 17000$ cal. yr B.P.; their slopes became relatively stable by $\sim 6000$ cal. yr B.P., were mantled by tephra from the $5600-5,900$ and $\sim 1100 \mathrm{cal}$. yr B.P. Plinian eruptions of Popocatépetl, and have been inactive for at least $200 \mathrm{yr}$, despite their young appearance. The younger and more active ravines were excavated in pyroclastic deposits from the last Plinian eruption $(\sim 1100$ cal. yr B.P $)$, during the final stages of the eruption or shortly thereafter. Today these ravines are characterized by unstable conditions and are episodically exposed to lahars, as is the case of the Huiloac ravine.

Keyzords: Popocatépetl volcano, ravines, dendrogeomorphology, post-eruptive erosion. 


\section{Introducción}

Los estudios sobre la evolución de los grandes aparatos volcánicos por lo general se centran en la reconstrucción de la historia eruptiva, en particular en las distintas fases de actividad. Menos atención reciben las transformaciones que sufren las laderas volcánicas durante las fases de inactividad. Si bien los episodios eruptivos representan etapas de enormes transformaciones en el relieve, los lapsos de quietud abarcan la mayor parte de la historia del relieve volcánico. Durante esos lapsos las geoformas pueden sufrir modificaciones significativas, sobre todo inmediatamente después de las erupciones, pero incluso durante la erupción misma, cuando prevalecen condiciones de gran inestabilidad geomorfológica y el relieve se transforma aceleradamente hacia una situación de nuevo equilibrio (Davidson y De Silva, 2000; Németh y Cronin, 2007; Gran et al., 201 1; Pierson y Major, 2014).

Las laderas del sector norte del Popocatépetl ubicadas entre los 4000 y los 3000 msnm (Figura 1a), presentan condiciones ideales para evaluar la magnitud de los procesos erosivos post-volcánicos, ya que fueron sepultadas por grandes volúmenes de materiales piroclásticos durante las fases eruptivas del Pleistoceno tardío y el Holoceno. En muchos casos fueron creadas superficies geomórficas completamente nuevas (rellenos de depósitos de flujos piroclásticos y laháricos en depresiones topográficas), mientras que en otros los depósitos sólo sepultaron parcialmente relieves anteriores, sin eliminarlos (depósitos piroclásticos de caída). Ambas situaciones permiten evaluar el papel geomorfológico de la actividad volcánica y post-volcánica. Recientemente Castillo et al. (2015) consideran que la actividad eruptiva actual del Popocatépetl mantiene en desequilibrio a los sistemas erosivos fluviales de la zona.

Las secuencias eruptivas del Popocatépetl se han estudiado con detalle en los últimos treinta años
(Robin, 1984; Robin y Boudal, 1987), en particular desde el inicio de la actual etapa eruptiva en 1994 (Siebe et al., 1996a, 1996b, 1996c, 1997; Panfil et al., 1999; Arana-Salinas et al., 2010; Sosa-Ceballos et al., 2012). Sin embargo, se sabe muy poco sobre lo sucedido entre una fase eruptiva y otra en cuanto a las transformaciones en el relieve, tanto en términos de erosión como de acumulación (por ejemplo, fases de incisión y colmatación en las barrancas y erosión en las laderas). La literatura señala que inmediatamente después de una fase eruptiva las laderas volcánicas pueden presentar gran inestabilidad y, por ende, transformaciones geomorfológicas significativas durante cierto tiempo, para gradualmente recuperar una condición de equilibrio (Segerstrom, 1950; Inbar et al., 1994; Manville et al., 2009; Gran et al., 2011; Pierson y Major, 2014).

En la presente investigación se determinó la edad relativa de cinco barrancas en la ladera norte del volcán Popocatépetl. Tres de ellas (B1, B2 y B3) están desconectadas de la estructura principal del volcán y se ubican en los límites con las formaciones del Iztaccíhuatl. Las otras dos barrancas (B4 y B5), están conectadas al edificio principal (Figura lb y 1c). Todas ellas fueron excavadas en depósitos de las erupciones plinianas del Popocatépetl de los últimos 17000 años cal. A.P. Con base en el análisis de la distribución, espesor, edad radiométrica $\left({ }^{14} \mathrm{C}\right)$ y preservación de los depósitos piroclásticos anteriores y posteriores a la formación de las barrancas, se pretende estimar la edad de formación y dinámica geomorfológica a través de las distintas fases eruptivas en cada barranca de estudio, comparando los dos tipos de barrancas mencionados. Por otro lado, se aplicaron técnicas dendrocronológicas para conocer las edades mínimas de las barrancas y algunos rellenos laháricos recientes, así como para determinar desde cuándo se encuentran estables las laderas, cabecera y fondos de las barrancas. 


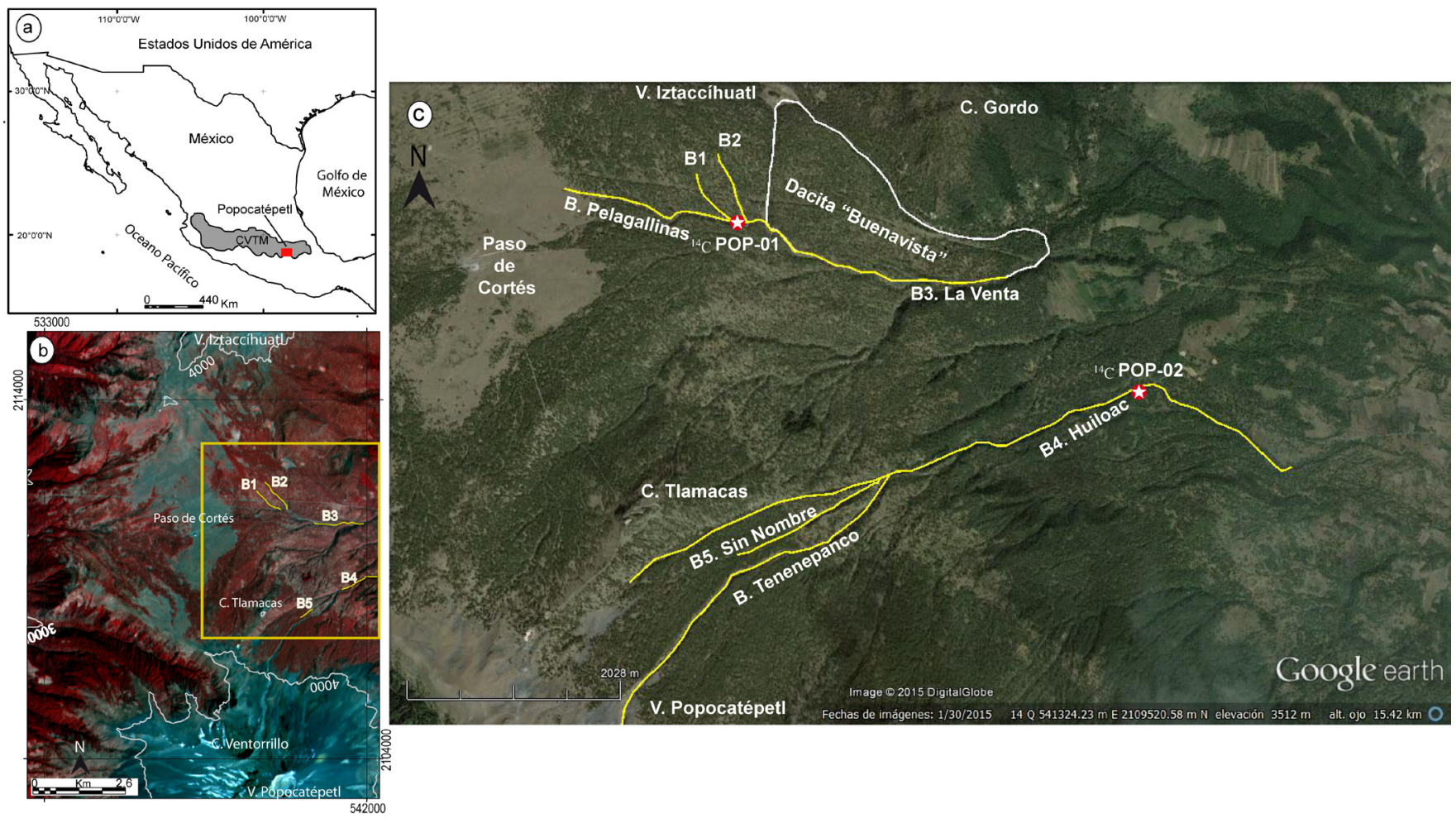

Figura 1 (a) Localización del volcán Popocatépetl en el centro-oriente del CVTM. (b) Las claves B1, B2, B3, B4 y B5, significan las cinco barrancas estudiadas. La imagen de satélite SPOT en compuesto RGB de falso color, muestra la cara norte del volcán y las barrancas estudiadas (líneas amarillas). El rectángulo amarillo indica la zona ampliada en c. (c) Imagen de satélite de Google Earth que muestra el detalle de las barrancas de estudio. Las estrellas blancas indican la localización de las muestras ${ }^{14} \mathrm{C}$.

\section{Marco geológico}

\subsection{EVOLUGIÓN DEL VOLGÁN POPOGATÉPETL}

El volcán Popocatépetl se localiza en el extremo sur de la Sierra Nevada, cordillera volcánica de edad Plio-Cuaternaria situada en el sector centro-oriente del Cinturón Volcánico Transmexicano (CVTM) (Figura la). La composición geoquímica de sus productos es dacítico-andesítica (Schaaf et al., 2005).

La evolución del volcán consta de al menos tres etapas de construcción y destrucción de edificios volcánicos (Robin y Boudal, 1987; Sosa-Ceballos et al., 2015). La primera se relaciona con la formación de un edificio volcánico construido hace $1 \times 10^{6}$ a, conocido por Robin (1984) como volcán primitivo o volcán Nexpayantla por Mooser
(1967). La edad del colapso no es clara, sin embargo, Macías (2005) estima que pudo ocurrir hace aproximadamente 200000 años A.P. La segunda etapa consiste en la formación de un nuevo edificio volcánico al interior de la caldera, nombrado El Fraile por Robin y Boudal (1987) o El Ventorrillo por Sosa-Ceballos et al. (2015). Aunque inicialmente se estimó la edad del colapsó entre 50000 y 30000 años A.P. (Robin y Boudal, 1987), trabajos más recientes sugieren que el colapso sucedió hace 23000 años A.P. (Siebe et al., 1996a; Macías, 2005; Sosa-Ceballos et al., 2015). Un tercer edificio volcánico pudo haber colapsado durante la explosión ocurrida hace 14100 años ( 17000 años cal. A.P.), evento conocido como erupción pliniana Tutti-Frutti (Sosa-Ceballos et al., 2012 y 2015). Desde entonces la acumulación de flujos de lava y depósitos piroclásticos han edificado el cono actual del Popocatépetl (Sosa-Ceballos et al., 2015). 


\subsection{ERUPGIONES PLINIANAS DEL POPOGATÉPETL DURANTE EL PLEISTOGENO TARDÍO-HOLOGENO}

El desarrollo del Popocatépetl durante la última etapa evolutiva ha estado dominado por eventos eruptivos plinianos. La de mayor magnitud ocurrió $\sim 17000$ años cal. A.P. La columna eruptiva alcanzó los $44 \mathrm{~km}$ de altura y se distribuyó hacia el NW, por lo que los materiales pudieron llegar hasta el territorio que ocupa la Ciudad de México y constituir parte de los componentes litoestratigráficos de la cuenca (Sosa-Ceballos et al., 2012). Los piroclastos resultantes se conocen originalmente como pómez con andesita (Mooser, 1967) y posteriormente fueron llamados depósitos Tutti-Frutti (Siebe et al., 1997).

Durante el Holoceno ocurrieron tres episodios plinianos. El primero produjo la llamada pómez Ocre alrededor de $4965 \pm 65{ }^{14} \mathrm{C}$ años A.P. (Siebe et al., 1996a; Arana-Salinas et al., 2010), cuya edad calibrada (2s) es de 5592 - 5891 años cal. A.P. (Stuiver y Reimer, 1993; Reimer et al., 2013). Inició con actividad freatomagmática que generó oleadas piroclásticas, seguidas por una fase pliniana que produjo pómez de caída de color ocre y composición andesítica, con líticos juveniles y accidentales, los primeros de color gris oscuro, los otros de limonita de coloración verde claro. Este evento culminó con la generación de flujos piroclásticos con distribución radial sobre las laderas del edificio principal.

El segundo evento pliniano del Holoceno tuvo lugar alrededor de 2200 - 2100 años cal. A.P., también conocida como pómez Lorenzo (Siebe et al., 1996b; Panfil et al., 1999). Comenzó con pequeñas explosiones que generaron depósitos de caída y flujo, y culminó con una columna pliniana, responsable de una capa de fragmentos angulosos de pómez de composición dacítica. El espesor promedio alcanzado fue de $1.10 \mathrm{~m}$. Su dispersión fue hacia el ENE con una cobertura elipsoidal y sepultó aldeas del periodo preclásico (Panfil et al., 1999). Además, se produjeron flujos de lava que cubrieron extensas áreas del sureste del volcán y alteraron el drenaje de la zona.
La erupción pliniana del Popocatépetl más reciente ocurrió alrededor de 1100 años cal. A.P. (entre $1275 \pm 60$ y $855 \pm 155$ años ${ }^{14}$ C A.P.) y produjo la pómez Pink (Siebe et al., 1996b). Ésta consta de al menos tres miembros asociados a sendos pulsos eruptivos. Se presume que la erupción causó un fuerte impacto en el medio ambiente y un despoblamiento de la región de Cholula. Siebe et al. (1997) identifican una primera erupción que arrojó pómez y líticos hacia el noreste (Miembro 1); en la segunda explosión los fragmentos fueron dispersados con una ligera tendencia hacia el este-noreste (Miembro 2); y la tercera erupción tuvo una dispersión hacia el este (Miembro 3). De acuerdo con Panfil et al. (1999) la secuencia se depositó en al menos dos eventos entre $\sim 1350$ y $\sim 1200$ años cal. A.P. Tanto Panfil et al. (1999) como González Huesca (2000) identificaron un depósito de lahar previo a los pulsos plinianos de esta erupción.

\section{Materiales y métodos}

El trabajo de campo se enfocó en el análisis estratigráfico y dendrogeomorfológico. De esta manera se estudiaron las secuencias volcánicas en las que se formaron las barrancas de la zona, por medio de secciones estratigráficas y correlación con trabajos previos. Se prestó especial atención a las secuencias de depósitos de caída presentes en las laderas de las barrancas, con objeto de determinar la edad relativa de la barranca con respecto a dichos depósitos. Se realizaron dos fechamientos por ${ }^{14} \mathrm{C}$ en depósitos volcanoclásticos de dos barrancas. Además, en campo se trazó el contorno de algunas barrancas con un Sistema de Posicionamiento Global (GPS), con error de $4 \mathrm{~m}$, para su localización y contexto geomorfológico.

El estudio dendrogeomorfológico se centró en la determinación de edades mínimas de superficies geomórficas con base en la edad de los árboles presentes en ellas (Stoffel y Bollschweiler, 2008). Para seleccionar los sitios de muestreo óptimos para el análisis dendrocronológico fue de mucha utilidad el reconocimiento previo de procesos geomorfoló- 
gicos, dinámica actual y disturbios en la zona de estudio. Este aspecto fue el punto de partida para la colecta de núcleos de árboles de dos especies de pino (Pinus hartwegii, Pinus ayacahuite) y una de abeto (Abies religiosa), con un total de 62 árboles. Para cada individuo se tomaron dos muestras en caras opuestas del tronco, con el fin de promediar la edad absoluta del árbol, siempre y cuando el número de anillos variara de 2 a 4 años.

En la preparación de las muestras se siguieron los protocolos de dendrocronología establecidos por Stokes y Smiley (1996) y Fritts (1976). Se utilizó un microscopio estereoscópico en el cual se hizo el conteo de anillos, se analizó el patrón de crecimiento y las irregularidades en los anillos y se determinó la edad de cada muestra (Stoffel y Bollschweiler, 2008; Villanueva et al., 2009; Stoffel y Corona, 2014). La curva de crecimiento de cada núcleo de crecimiento y la correlación entre ellos para identificar anillos faltantes o dobles, se obtuvo mediante el programa TSAP-Win (Rinntech, 2014).

Para saber las edades mínimas de relieve, las edades de los árboles muestreados fueron calibradas considerando el periodo de estabilización, germinación y crecimiento de los árboles sobre superficies post-volcánicas, como sugiere Koch (2009). La écesis (periodo de germinación y establecimiento de una planta sobre superficies nuevas) varía en función de la especie, las condiciones ambientales, morfodinámicas y morfométricas de cada zona de estudio, y puede ser desde un año hasta varias décadas (Villalba, 2000). En terrenos volcánicos de las Cascadas (E.U.A), la écesis del abeto Douglas después de la estabilización geomorfológica llega a ser de cuatro años, mientras que el tiempo que tarda el árbol en crecer a la altura del pecho $(\sim 1.35$ $\mathrm{cm}$, nivel de toma de muestras), es de 11 años en promedio, con lo cual la calibración de la écesis llega a ser de hasta 15 años (Pierson, 2007). Para las especies de árbol muestreadas en este estudio Muñoz-Jiménez et al. (2005) identificaron un ritmo de colonización relativamente rápido sobre las terrazas originadas por los lahares de 1997 y 2001 en la barranca Huiloac (NE del Popocatépetl). Consideran que 2 años son los que transcurren entre la estabilización de la superficie geomórfica y la germinación de un pino. No obstante, por las condiciones de estrés (suelos someros), los pinos crecen a un ritmo lento y en muchos casos no sobreviven a la primera década. En este trabajo, las edades de los árboles se calibraron estimando 10 años de écesis para las barrancas de estudio. La suma de estos 10 años con las edades de los árboles contados, permite tener mayor exactitud en la edad del relieve, aunque es importante enfatizar que se trata de edades mínimas.

A partir del conteo de anillos de crecimiento se fecharon árboles que crecen al interior de las barrancas (laderas, cabecera y fondo o canal), con objeto de obtener edades mínimas de las mismas. La premisa básica es que los árboles se establecen y sobreviven en superficies geomorfológicamente estables, es decir, ahí donde la actividad erosiva o acumulativa ha cesado o disminuido significativamente. Por su longevidad de décadas o siglos, los árboles pueden utilizarse como indicadores de estabilidad geomórfica de largo plazo. Estudios previos de dendrocronología en diversas montañas de México han demostrado que la especie Pinus hartwegii puede alcanzar edades de $>600$ años (Villanueva et al., 2010) y Abies religiosa > 200 años.

$\mathrm{Al}$ interior de las barrancas se observaron las siguientes situaciones dendrogeomorfológicas: (i) un árbol de 100 años de edad que crece en la ladera de una barranca indica que la actividad erosiva de las laderas asociada a la incisión cesó hace al menos 100 años. (ii) otro individuo de 50 años, sin disturbios en el tronco y raíces, desarrollado en el lecho de la barranca revela que en ese sitio no ha ocurrido erosión vertical, lateral ni acumulación (coluvial y/o aluvial) significativas al menos desde hace 50 años. (iii) árboles inclinados sugieren procesos de ladera activos. (iv) la edad del arbolado puede indicar el tiempo de existencia de geoformas tan específicas como las terrazas. (v) un árbol de 80 años que crece en una cabecera fluvial (sector más dinámico de una barranca, donde ocurren 
los procesos de erosión remontante) indica que el terreno ha permanecido estable, sin retroceder, al menos desde hace ocho décadas.

\section{Resultados}

\subsection{EDAD Y DINÁMICA DE LAS BARRANGAS}

El análisis de la estratigrafia muestra que el sector N-NE del Popocatépetl (Figura 1b, c), ha sido cubierto por diversas secuencias plinianas (caídas) y depósitos de flujos piroclásticos asociados. La barranca Huiloac y anexas se generaron sobre potentes depósitos de flujo piroclástico (además de los de caída) asociados a la erupción de $\sim 1100$ años cal. A.P., mientras que la zona localizada al norte (donde se encuentran las barrancas de Pelagallinas y La Venta) no llegaron estos depósitos volcánicos, debido a que los relictos caldéricos de Tlamacas, lo impidieron. Por lo tanto en este último sector sólo se reconocen depósitos de flujo asociados a la erupción Tutti-Frutti de hace $\sim 17000$ años cal. A.P., cubiertos por las caídas plinianas más recientes.

\subsubsection{B1. PRIMER AFLUENTE DE LA BARRANCA PELAGALLINA}

Un corte a través de su ladera sur muestra que esta barranca corta en depósitos de flujo piroclástico de la secuencia Tutti-Frutti de hace $\sim 17000$ años cal. A.P. (Sosa-Ceballos et al., 2012) y este depósito se encuentra manteado por la pómez Ocre de 5900 5600 años cal. A.P. (Siebe et al., 1997) (Figura 2). El espesor de la pómez Ocre en el sitio es de $60 \mathrm{~cm}$. Fragmentos de carbón encontrados en un depósito de flujo piroclástico por debajo de un paleosuelo

\section{Barranca principal Pelagallinas}

(m) Superficie cumbral

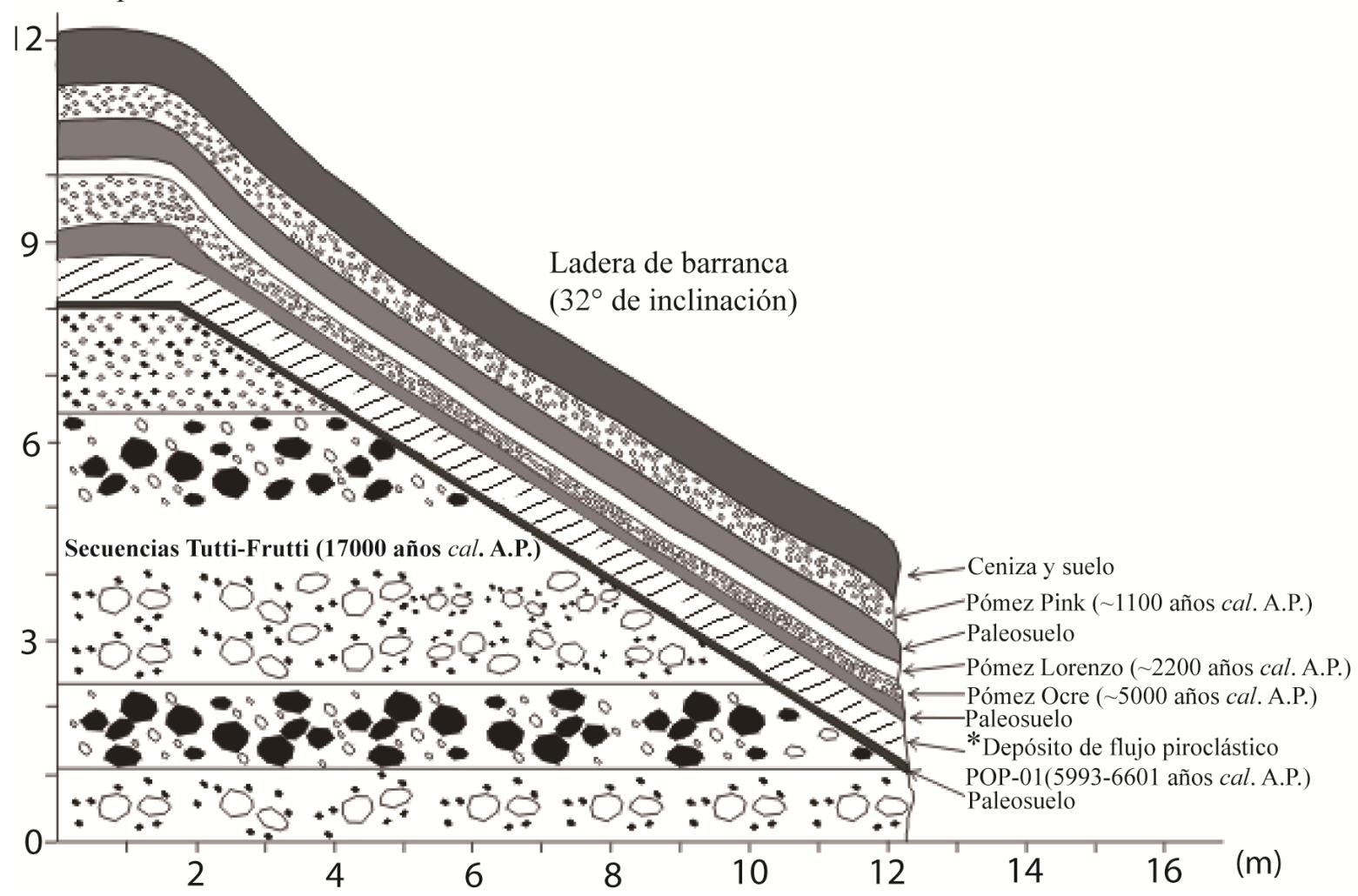

Figura 2 Estratigrafía de la barranca Pelagallinas, localizada en la ladera norte del Popocatépetl. El dato señalado por el asterisco corresponde al carbón fechado por ${ }^{14} \mathrm{C}$, resultado de esta investigación. 
que a su vez subyace a la pómez de caída Ocre arrojan una edad (2s) de 5993 - 6601 años cal. A.P. (5515 \pm 125/-120 años ${ }^{14}$ C A.P.) (POP-01 en Figura 2 y Tabla 1). Esta edad resulta congruente con la de 5592 - 5891 años cal. A.P. de la pómez Ocre (Arana-Salinas et al., 2010).

La presencia de un paleosuelo sobre la secuencia de pómez Lorenzo indica un periodo de calma eruptiva, que terminó con el depósito de la capa de pómez de caída de la erupción de $\sim 1100$ años cal. A.P. (Siebe et al., 1997). Cabe mencionar que sobre las laderas de la barranca, a pesar de su fuerte pendiente $\left(32^{\circ}\right)$, las pómez de caída de 5600 - 5900 y $\sim 1100$ años cal. A.P. forman capas continuas con espesores menores que en las superficies de poca inclinación fuera de la barranca (Figura 2). Lo anterior indica que la formación y desarrollo de esta barranca y otros similares ocurrió en una etapa de inestabilidad geomorfológica post-Tutti-Frutti, entre $\sim 17000$ y $\sim 6000$ años cal. A.P. La fecha POP-01 de 5993 - 6601 cal. A.P. $\left(5515 \pm 125 /-120\right.$ años ${ }^{14}$ C A.P. $)$ representa el inicio de la estabilización de las laderas de la barranca principal Pelagallinas, ya que sobreyace directamente al primer suelo formado en la ladera de la barranca. Los eventos plinianos posteriores mantearon la barranca, que ya se encontraba estabilizada. En otras palabras, en los últimos $\sim 6000$ años cal. A.P. las laderas de la barranca prácticamente no han estado activas, como indica la presencia de las pómez Pink y Ocre in situ en laderas con pendiente de $>30^{\circ}$. En las laderas de ésta y las barrancas afluentes, la estratigrafía es similar a la de la Figura 2, sin embargo los espesores varían y ocasionalmente falta alguna capa (por ejemplo la pómez Lorenzo, que es muy delgada en esa zona). La dinámica morfológica reciente de la barranca Pelagallina se evaluó mediante métodos dendrocronológicos. Para este fin se colectaron 21 núcleos de árboles en 12 especímenes de Pinus hartwegii distribuidos en distintas unidades geomorfológicas al interior de las barrancas como cabecera, ladera y lecho aluvial (Figura 3). Con base en los estimados dendrocronológicos, es posible afirmar que las laderas de la barranca se encuentran estables desde hace al menos $\sim 135$ a $\sim 210$ años. La existencia de arbolado en las cabeceras, indica la ausencia de procesos erosivos importantes desde hace al menos $\sim 95$ años. El retroceso de este sector se considera de los últimos procesos geomorfológicos en detenerse, lo cual se sustenta por la presencia de árboles más jóvenes en las cabeceras que en las laderas de la barranca; mientras en el lecho aluvial, no han ocurrido procesos de erosión-acumulación significativos al menos en los últimos $\sim 105$ años (edad del árbol más viejo muestreado). Lo anterior permite concluir que la fase erosivo-acumulativa del lecho de esta barranca concluyó hace poco más de 6000 años cal. A.P. y tiende a la estabilidad geomorfológica desde entonces.

Los datos estratigráfícos y dendrocronológicos obtenidos permiten concluir que la excavación de la barranca concluyó hace poco más de 6000 años; que las laderas se han mantenido estables desde entonces, no obstante la caída episódica de pómez y ceniza; que al menos en los últimos $\sim 210$ años las laderas se encuentran inactivas (bajo cubierta forestal) y las cabeceras no han cambiado de po-

Tabla 1. Fechamientos ${ }^{14} \mathrm{C}$ de las dos muestras tomadas en depósitos volcánicos de las barrancas Pelagallinas y Huiloac. Datum de las coordenadas UTM: WGS-84.

\begin{tabular}{|c|l|c|c|c|c|}
\hline MUESTRA & UTM & MATERIAL & EDAD AÑOS ${ }^{\mathbf{1 4} \text { C. A.P }}$ & EDAD CAL. 1S. A.P * & EDAD CAL. 2S. A.P * \\
\hline POP-01 & $\begin{array}{l}\text { X. } 539464 \\
\text { Y. } 2111024\end{array}$ & Carbón & $5515 \pm 125 /-120$ & $6183-6451$ & $5993-6601$ \\
\hline POP-02 & $\begin{array}{l}\text { X. } 543469 \\
\text { Y. } 2109951\end{array}$ & Carbón & $1105 \pm 40$ & $966-1056$ & $930-1166$ \\
\hline
\end{tabular}

* Calibración usando el programa Calib Rev 5.0 (INTCAL04.14C). 


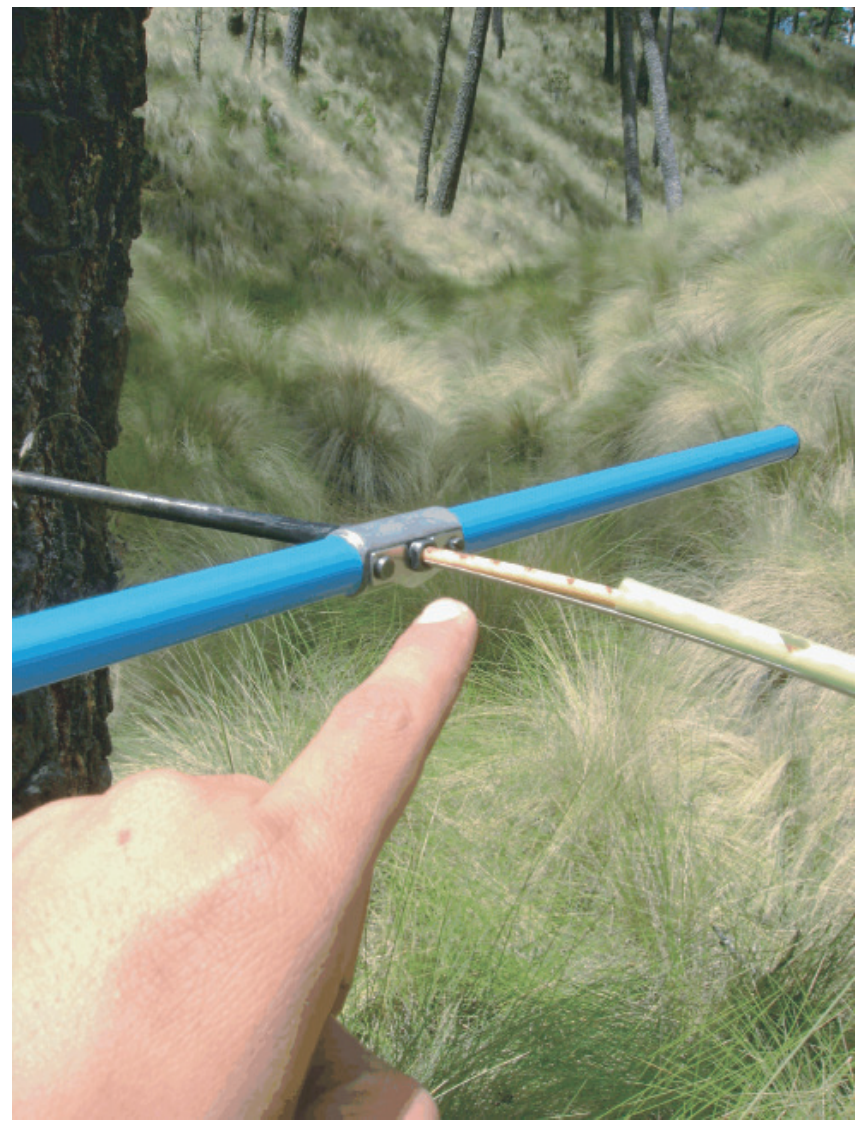

Figura 3 Colecta de muestras dendrocronológicas para determinar edades mínimas del relieve y estabilidad de procesos geomorfológicos en el primer afluente de la barranca Pelagallinas (B1).

sición al menos en los últimos $~ 95$ años, en tanto que el lecho se ha mantenido estable al menos en los últimos $\sim 105$ años.

\subsubsection{B2. SEGUNDO AFLUENTE DE LA BARRANCA PELAGALLINA}

Las secuencias volcánicas de este sitio son las mismas que el caso anterior, solo que con ligeras variaciones en los espesores de los depósitos. Sin embargo, en esta barranca se observan condiciones de mayor inestabilidad geomorfológica, ya que actualmente el lecho de la barranca está siendo incidido por procesos fluviales, sobre todo en la temporada húmeda del año. Evidencia de lo anterior, es la presencia de zapa sobre la base de las laderas de la barranca, lo que favorece la ocurrencia de pequeños deslizamientos.
No obstante lo anterior, con base en la edad del arbolado (21 núcleos en 11 árboles de P. hartwegii), se puede decir que no ocurren procesos de ladera significativos en esta barranca desde hace al menos 140 años. Las cabeceras tanto de la barranca principal como de su pequeño afluente son los rasgos geomorfológicos más jóvenes, ya que las edades de los árboles que ahí se desarrollan están entre 80 y $\sim 120$ años. La muestra PO-14 es un árbol de 136 años que se encuentra a $\sim 4 \mathrm{~m}$ de la cabecera actual, con lo cual puede inferirse que la cabecera ha retrocedido como máximo $4 \mathrm{~m}$ en los últimos 136 años (Figura 4).

Para la incisión vertical se tomó como referencia una terraza (antiguo lecho aluvial) dentro de la barranca principal. El desnivel entre la terraza y el lecho actual de la barranca es de $\sim 1 \mathrm{~m}$, superficie sobre la que se muestreó el árbol PO-20, cuya edad es de 119 años. Esto quiere decir que la erosión concentrada en el fondo de la barranca es relativamente lenta, ya que en un lapso de al menos 120 años la barranca se encajó solamente $1 \mathrm{~m}$.

\subsubsection{B3. BARRANGA LA VENTA}

Su origen y desarrollo se remontan al emplazamiento de un flujo de lava emanado de una fisura (dacita Buenavista de Nixon, 1989), que rellenó parcialmente una barranca excavada en depósitos

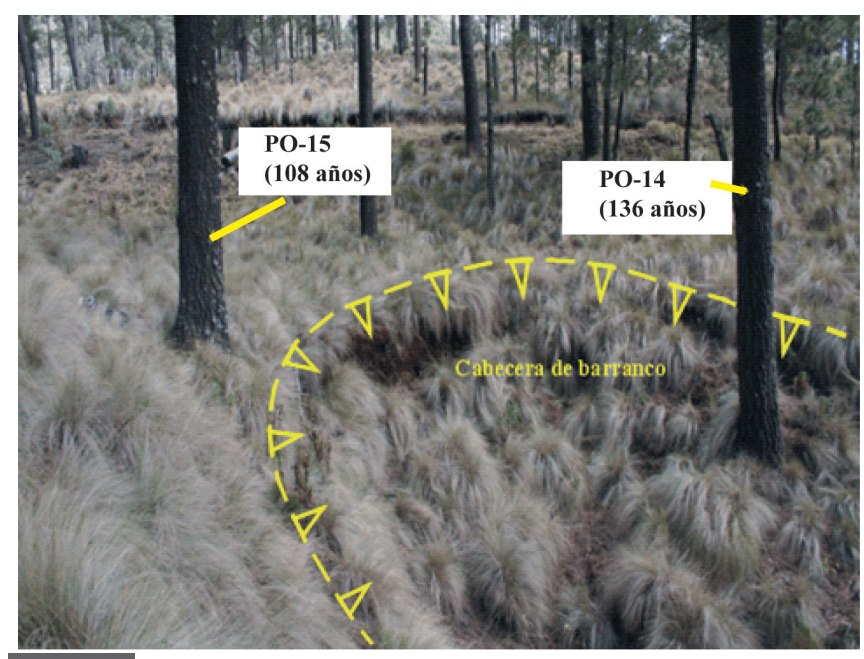

Figura 4 Cabecera del segundo afluente de la barranca Pelagallinas. Nótese las condiciones de estabilidad geomorfológica de hace al menos 108 años. 
Tutti-Frutti de hace 17000 años cal. A.P. (Siebe et al., 1997). Procesos erosivos fluviales han ocurrido a lo largo del contacto del flujo lávico y los depósitos piroclásticos Tutti-Frutti, creando una nueva barranca. Posteriormente tanto la nueva barranca como la lava, fueron cubiertas por secuencias plinianas del Holoceno (Figura 5), por lo que se infiere que tanto la emisión del flujo de lava como la formación de la nueva barranca ocurrieron entre $\sim 17000$ y $>5900-5600$ años cal. A.P., siendo esta última la edad de la pómez Ocre.

Para evaluar la dinámica reciente de La Venta por medio de dendrogeomorfología, se colectaron 34 muestras de árbol en 17 especímenes de Pinus hartwegii, localizados al interior de la barranca, a un altitud promedio de $3400 \mathrm{msnm}$. Con base en la edad de los árboles se infiere que las laderas de la barranca se estabilizaron hace al menos 160 años. Las unidades geomorfológicas más jóvenes son las terrazas fluviales. Las muestras PO-51 y PO-52 son árboles con edades de $\sim 60$ años que se encuentran sobre una pequeña terraza de $\sim 60$ $\mathrm{cm}$ de alto. Esto sugiere que la incisión vertical en el lecho fluvial en este sector de la barranca ocurre a una tasa no mayor de $\sim 1 \mathrm{~cm}$ por año (Figura 5).

\subsubsection{B4. BARRANCA HUILOAC}

La barranca Huiloac es una de las más activas del Popocatépetl. Desciende por el lado NE del volcán y desemboca en el pueblo de Santiago Xalitzintla. El tramo estudiado se ubica $\sim 7.5 \mathrm{~km}$ al NNE del cráter (B4 en la Figura 1c). El análisis morfo-estratigráfico indica que la barranca fue enteramente excavada en depósitos piroclásticos (flujo y caída) de la última erupción pliniana de hace $\sim 1100$ años cal. A.P. Estos depósitos fueron cortados por la dinámica fluvial post-volcánica, resultando una barranca con laderas de $>30 \mathrm{~m}$ de profundidad y

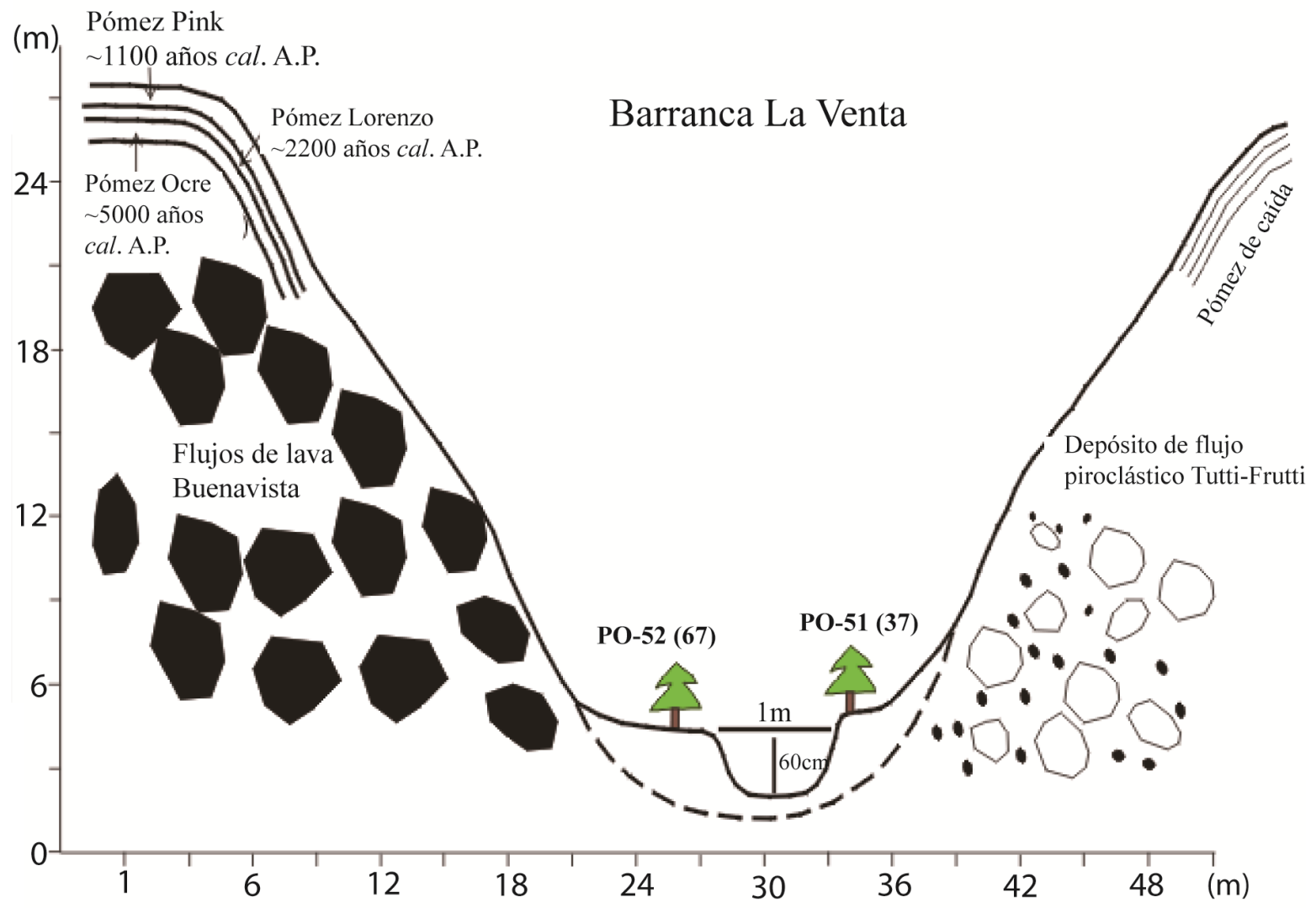

Figura 5 Estratigrafía y edades dendrocronológicas de la barranca La Venta (B3). Los datos entre paréntesis son las edades calibradas de los árboles 
$45^{\circ}$ de inclinación. En la parte más alta de las paredes de la barranca, cubriendo a varios depósitos de flujo piroclástico de $\sim 20 \mathrm{~m}$ de espesor, es posible reconocer uno de los miembros de caída de la pómez Pink con un espesor de $60-80 \mathrm{~cm}$ (presumiblemente el miembro 1 ó 2 de la erupción en la estratigrafía de Siebe et al., 1996a). A estos materiales sobreyacen depósitos de flujos de escombros de $1.5 \mathrm{~m}$ y un horizonte de ceniza gris oscuro de $80 \mathrm{~cm}$, aparentemente asociados al mismo evento de $\sim 1100$ años cal. A.P. (Figura 6).

Dentro de la barranca, a una altitud entre 3400 y $3200 \mathrm{msnm}$, es posible observar una terraza de varios metros de altura. Esta se originó por un relleno de depósitos de lahar que posteriormente fueron excavados verticalmente, dejando terrazas laterales a lo largo de la barranca de $\sim 8 \mathrm{~m}$ (localmente hasta $12 \mathrm{~m}$ ) de altura sobre el fondo actual. Hay que señalar que en los depósitos laháricos de esta terraza, no se encuentra in situ ninguno de los miembros de la erupción Pink, por lo que interpretamos que los depósitos laháricos son posteriores a las caídas de pómez pliniana.

$\mathrm{El}$ relleno lahárico que compone a esta terraza consiste de clastos de pómez subredondeados y redondeados de los colores típicos de la pómez Pink (10YR 8/1, 10YR 7/1, 5YR 7/2), pobre en líticos, envueltos en una matriz de ceniza de color gris oscuro, de tamaño arena gruesa, de $8-12 \mathrm{~m}$ de espesor, con estratificación cruzada, en estratos comúnmente de $10-20 \mathrm{~cm}$ de espesor. Dentro de los depósitos laháricos, a $8 \mathrm{~m}$ por encima del cauce actual, se encontró un fragmento de madera carbonizada de $6 \mathrm{~cm}$ de diámetro, claramente redondeado durante el transporte, mismo que se utilizó para fechar este depósito por el método de ${ }^{14} \mathrm{C}(\mathrm{Fi}$ gura 6). La edad de la muestra de carbón POP-02, es de $1105 \pm 40$ años ${ }^{14}$ C A.P. $(931-1172$ años cal. A.P.) (Tablal). Lo que hace suponer que la terraza observada al interior de la barranca se originó por

\section{Barranca Huiloac Ceniza gris y suelo}

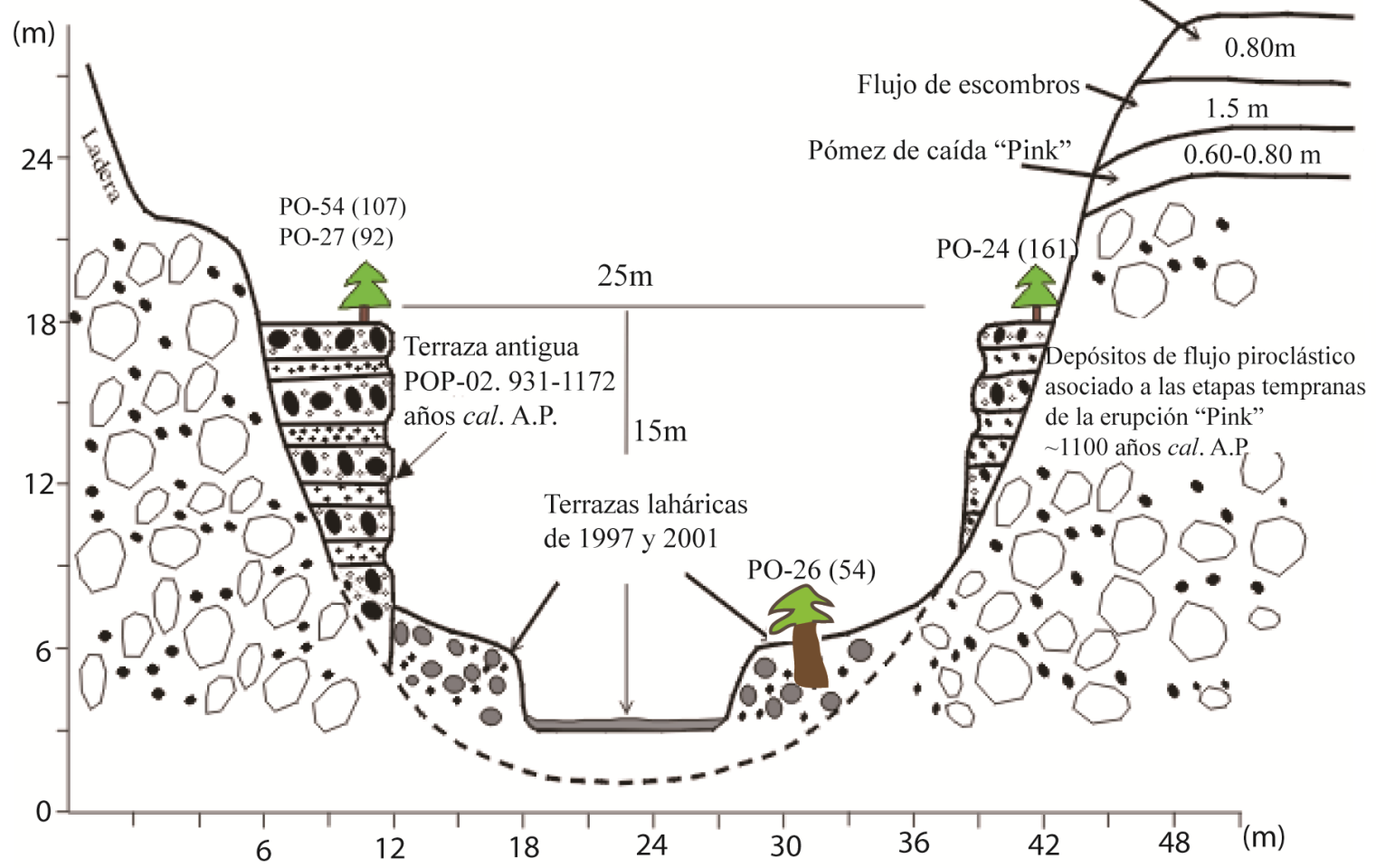

Figura 6 Estratigrafía y fechamientos dendrocronológicos de la barranca Huiloac (B4). Los datos entre paréntesis son las edades calibradas de los árboles 
un relleno lahárico emplazado poco después de los eventos de caída Pink (miembro 3). Esta idea se sustenta en la ausencia de suelos sepultados entre los depósitos expuestos en la barranca; en la ausencia de la pómez de caída o depósitos de flujo piroclástico de la erupción Pink dentro la secuencia de depósitos que componen el relleno lahárico; y por supuesto en el fechamiento por ${ }^{14} \mathrm{C}$ POP-02 que coincide con los fechamientos reportados por Siebe et al. (1996a) y por Panfil et al. (1999) para la erupción de $\sim 1100$ años cal. A.P. (Tabla 1).

Con base en el fechamiento por ${ }^{14} \mathrm{C}$, se puede decir que la edad máxima de la terraza es de 930 - 1170 años cal. A.P. Por otro lado se intentó determinar la edad mínima de la terraza lahárica por medio del fechamiento dendrocronológico de árboles que crecen sobre su superficie, resultando edades mucho más recientes (Figura 6). El árbol más antiguo muestreado (muestra PO-24) arroja una edad de 161 años, que representa la edad mínima para la terraza. Bollschweiler et al. (2010) reportan un árbol que data del año 1795 creciendo sobre la misma terraza. En suma, los datos dendrocronológicos indican que la terraza ya existía a fines del siglo XVIII.

Cabe mencionar que Panfil et al. (1999) y González-Huesca (2000) encontraron un depósito lahárico en sectores más bajos de esta misma barranca (área de San Nicolás de los Ranchos). Este depósito no corresponde al lahar arriba descrito ya que subyace a los miembros de pómez de caída pliniana, es decir, que se produjo en la fase temprana de la erupción de hace $\sim 1100$ años cal. A.P. Existen otras fases de rellenamiento e incisión que se pueden observar en la barranca Huiloac, vinculadas con los lahares que se emplazaron durante las explosiones del Popocatépetl ocurridas en 1997 y 2001 (Capra et al., 2004). Evidencias de este proceso son terrazas de relativa juventud que se encuentran de 1 a $5 \mathrm{~m}$ por encima del lecho actual. Se trata de depósitos heterométricos, ricos en fragmentos de líticos y de pómez, de subredondeados a subangulares y con distintos espesores. El árbol correspondiente a PO-26 tiene una edad de 54 años (Figura 6), lo cual quiere decir que este individuo ya existía cuando se emplazaron los últimos eventos laháricos de 1997 y 2001, mismos que dejaron cicatrices de impacto y relleno de sedimentos en éste y otros troncos de árboles expuestos a los lahares, localizados en los bordes del canal y en las laderas bajas de la barranca.

En este mismo tramo, del sector medio de la barranca Huiloac (3200 - 3300 msnm), se colectaron un total de 17 núcleos en 13 árboles (Pinus ayacahuite y Abies religiosa), en distintos niveles de terrazas, la edad de los más altos y antiguos es de $\sim 160$ años y se localizan sobre la terraza de $\sim 1100$ años cal. A.P. Las terrazas relativamente más jóvenes datan de 50 a 70 años como mínimo. Estos resultados sugieren la existencia de varios procesos de depósito y erosión fluvio-volcánicos en el interior de la barranca, así como distintas fases de sucesión de la cubierta vegetal, debido a la mayor dinámica geomorfológica en este sector de la barranca.

\subsubsection{B5. BARRANGA "SIN NOMBRE"}

El quinto caso corresponde a una pequeña barranca que se localiza entre la cañada Tenenepanco-Huiloac y Tlamacas (ladera norte del Popocatépetl), en un rango de altitud entre los 3700 y $3720 \mathrm{msnm}$. Su origen se asocia a una superficie de acumulación, con varias fases de erosión-depósito de flujos de escombros, posteriores a la erupción pliniana de hace $\sim 1100$ años cal. A.P. De la misma manera que los sectores intermedios de la barranca Huiloac (B4), estos depósitos no se relacionan con los lahares reportados por González Huesca (2000), durante las fases tempranas de la erupción Pink ocurrida hace unos 1300 años cal. A.P.

En campo se pueden distinguir al menos dos fases de relleno e incisión de aspecto reciente (Figura 7). La primera constituida por material lahárico (flujos de escombro, presumiblemente del evento de hace $\sim 1100$ años cal. A.P.) que cubrió esta zona y a su vez fue cubierto por una capa de ceniza gris similar a la observada en la barranca Huiloac en la parte más alta de la secuencia de $\sim 1100$ años cal. A.P. (Figura 6). Posteriormente un lahar rellenó parcialmente la barranca con un depósito rico en líticos en una matriz de arena gruesa. Unos me- 


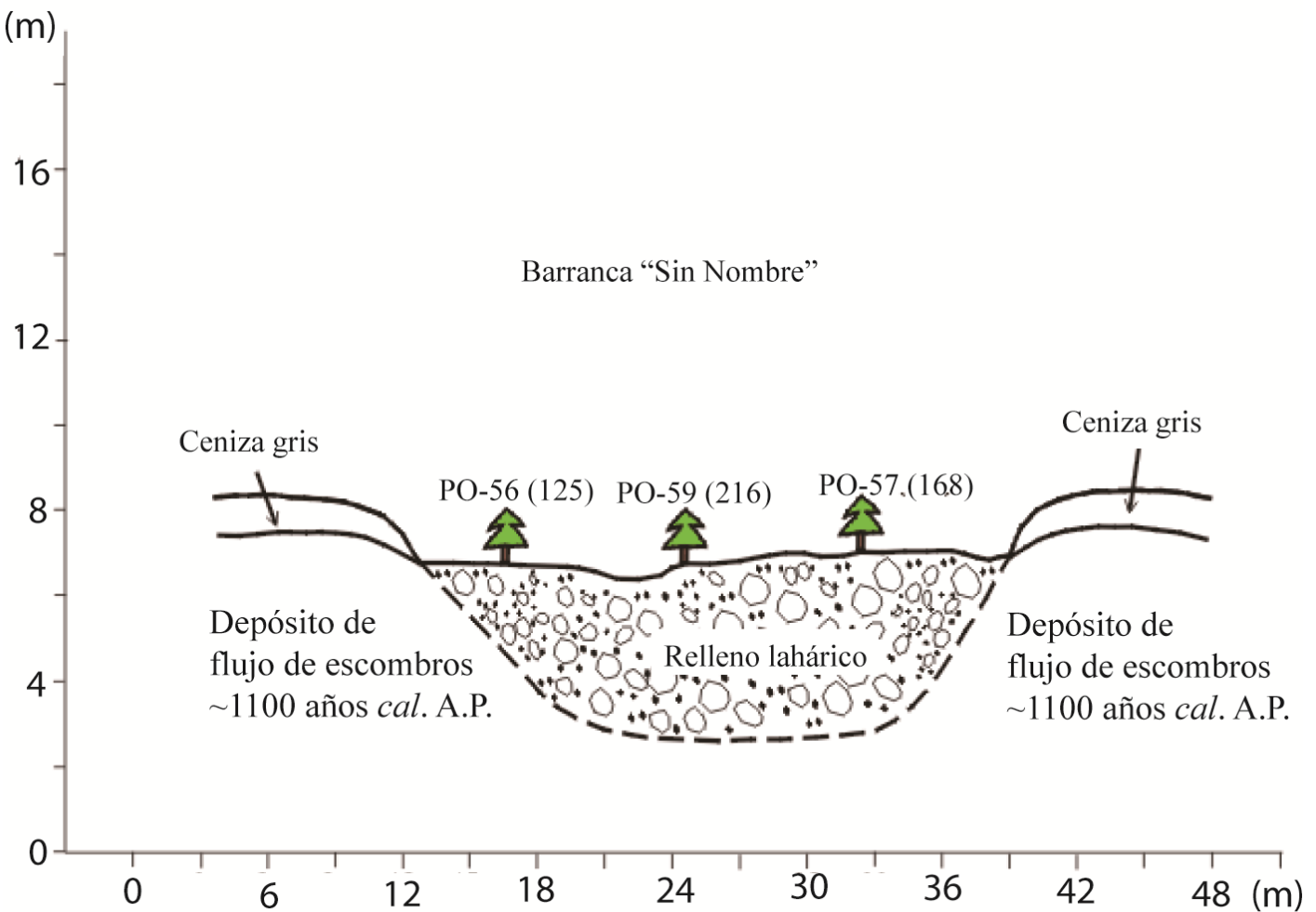

Figura 7 Estratigrafía y edad del arbolado en la barranca "sin nombre" (B5) (coordenadas UTM aproximadas: x: 540261; y: 21080554). Los datos entre paréntesis son las edades calibradas de los árboles.

tros aguas abajo del sitio de la Figura 7, se observa que el depósito se adelgaza y termina en forma de lóbulo en el interior de la misma barranca. Cabe destacar que sobre estos materiales de relleno, no se distingue la ceniza gris, lo que hace suponer que este nuevo depósito sea más reciente que la erupción de $\sim 1100$ años cal. A.P.

Para conocer las edades mínimas del depósito lahárico, se tomaron 18 muestras dendrocronológicas en 9 individuos de Pinus hartwegii. Las edades de los árboles sugieren que la edad mínima del relleno es de 216 años (muestra PO-59), mientras que la edad máxima es la de los productos de la erupción de $\sim 1100$ años cal. A.P.

\subsection{TIPOLOGÍA DE BARRANCAS}

Con base en los resultados de cada uno de los casos de estudio, se elaboró una tipología de barrancas del sector norte del Popocatépetl. El mapa que se presenta en la Figura 8, se obtuvo extrapolando la información morfo-estratigráfica y dendrogeomorfológica, vista en campo y analizada en gabinete. Para este fin se foto-interpretó una tripleta de fotografías aéreas a escala 1:37500, clasificando las barrancas del sector norte en función a la edad y dinámica actual del relieve. Se obtuvieron cuatro categorías de barrancas.

\subsubsection{BARRANCAS ESTABLES}

Son barrancas originadas entre $\sim 17000$ y poco más de 6000 años cal. A.P., se consideran estables desde hace el menos 200 años, con posible actividad menor en sus cabeceras hace alrededor de 100 años. Son ejemplos de este tipo los dos afluentes de la cañada Pelagallinas (B1 y B2).

\subsubsection{BARRANGAS MODERADAMENTE ESTABLES}

Se excavaron después de la erupción Tutti-Frutti hace unos $\sim 17000$ años cal. A.P. bajo un ambiente periglacial altamente dinámico; presumiblemente alcanzaron dimensiones similares a las actuales 


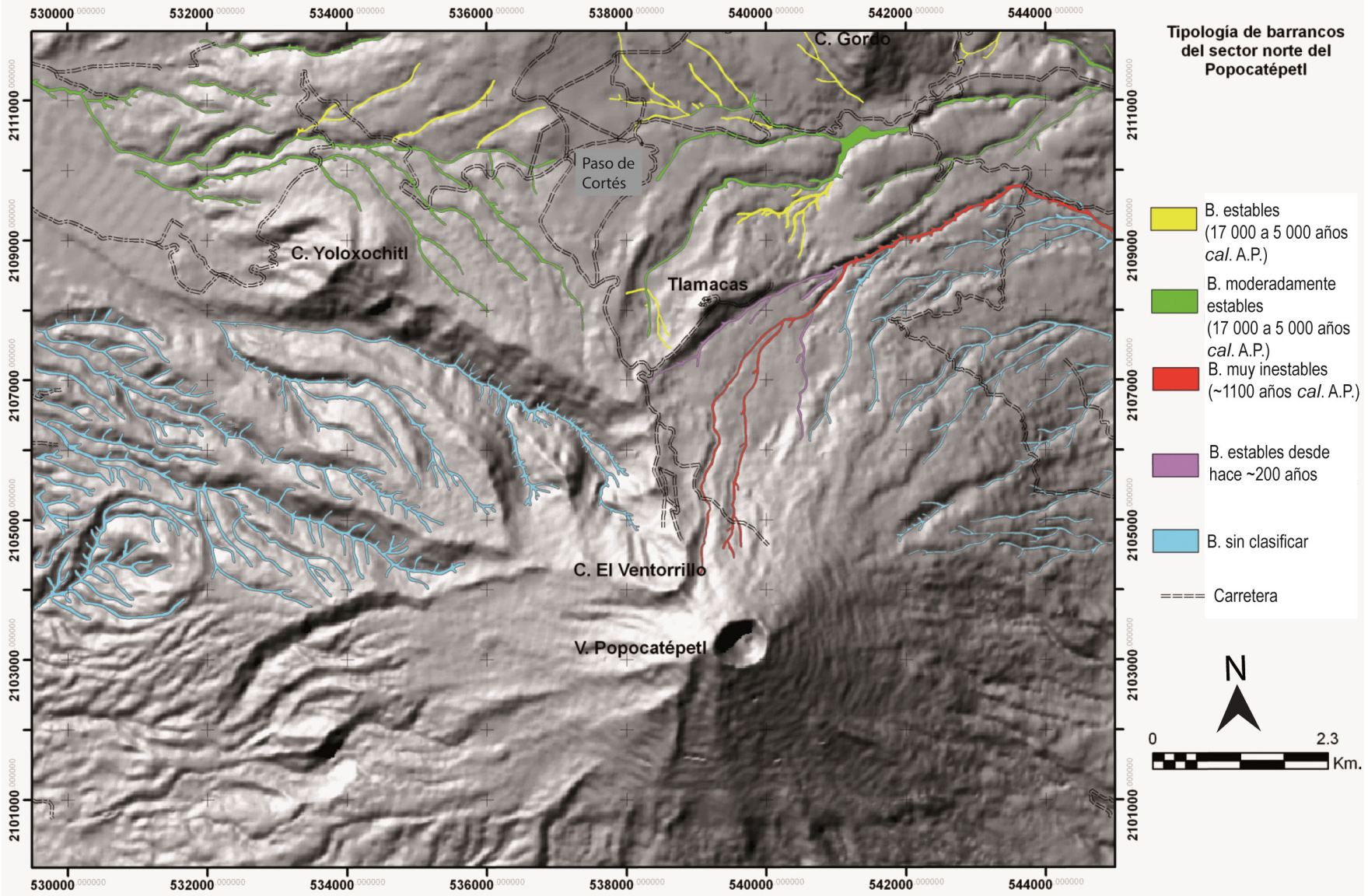

Figura 8 Mapa de tipología de barrancas del sector norte del Popocatépetl. Se reconocieron 4 tipos, de los más antiguos y estables a los más recientes y dinámicos.

poco tiempo después de la actividad volcánica; sin embargo, sus laderas permanecieron con cierta erosión hasta poco antes de la caída de la pómez Ocre, hace unos 6000 años cal. A.P. Tanto esta pómez como otras tefras posteriores han manteado las barrancas y permanecido en sus laderas. Aunque sus laderas están fundamentalmente estables desde hace al menos 150 años, tienen actividad en el fondo desde hace al menos $\sim 70$ años. Este tipo está representado por una dinámica geomorfológica similar a la ocurrida en las barrancas La Venta y Pelagallina. Se consideran moderadamente estables (B3).

\subsubsection{BARRANCAS MUY INESTABLES}

Son aquellas que se formaron hace $\leq 1100$ años cal. A.P. por disección de los productos e flujo y caída de la última gran erupción del Popocatépetl, y tienen su área de captación en laderas altas del volcán. Se activan durante las fases eruptivas, conduciendo flujos laháricos. Son considerados como muy inestables, siendo la barranca Huiloac un ejemplo de este tipo (B4).

\subsubsection{BARRANCAS ESTABLES DESDE HACE 200 AÑN}

Se formaron hace $\leq 1100$ años cal. A.P. En origen son similares al caso de Huiloac, pero sus cabeceras fueron rellenas por lahares y con ello quedaron desconectados de su antigua cuenca alimentadora, lo que los hace similares al tipo B1 y B2. Son relativamente estables desde hace al menos $\sim 215$ años, aunque pueden reactivarse en fases eruptivas debido la proximidad del cráter, barrancas tipo B5. 


\section{Discusión y conclusiones}

El análisis morfo-estratigráfico en terrenos volcánicos es útil para identificar secuencias eruptivas relacionadas con la génesis y evolución del relieve. La interpretación de las edades de las barrancas del sector norte del Popocatépetl se basó en la identificación de las tefras previamente reconocidas y fechadas por Siebe et al. (1996b, 1997), Panfil et al. (1999) y Arana-Salinas et al. (2010).

Con base en el conocimiento de las edades de los materiales, se considera que la mayoría de las barrancas del sector norte fueron excavadas en depósitos Tutti-Frutti de hace $\sim 17000$ años cal. A.P. y posteriormente manteadas por las tefras Ocre (5600 - 5900 años cal. A.P.) y Pink ( 1100 años cal. A.P.). Esto indica que la dinámica erosiva formadora de las barrancas actuales ocurrió después del emplazamiento de los depósitos Tutti-Frutti y antes del evento eruptivo de la pómez Ocre, con una clara tendencia a la estabilidad geomorfológica desde hace unos 6000 años cal. A.P.

Los fechamientos realizados por ${ }^{14} \mathrm{C}$ complementan y corroboran los resultados de las edades de las tefras determinados en estudios previos y permiten precisar la edad de la formación y desarrollo de las barrancas. La muestra de carbón POP-01 que se colectó dentro de un depósito piroclástico debajo de un paleosuelo sepultado por la pómez Ocre, data de 5990 - 6600 años cal. A.P (5515 \pm $125 /-120$ años ${ }^{14} \mathrm{C}$ A.P). Esto es congruente con la edad del evento eruptivo inmediatamente posterior denominado Ocre, de 5590 - 5890 años cal. A.P. (4965 \pm 6 años ${ }^{14}$ C A.P.) (Arana-Salinas et al., 2010). Es importante porque señala que en las laderas de la barranca Pelagallinas prevalecieron condiciones de inestabilidad geomorfológica desde la erupción Tutti-Frutti $(\sim 17000$ años cal. A.P.) hasta un poco antes de la caída de la pómez Ocre, cuando se desarrolló por primera vez un suelo en dicha ladera. Esta fase de pedogénesis debió ocurrir entre $\sim 6600$ años cal. A.P. (fechamiento POP-01 de este trabajo) y $\sim 5750$ años cal. A.P. (Pómez Ocre) (Figura 2).
El inicio de la estabilización geomórfica de las barrancas manteadas por la pómez Ocre de $~ 5750$ años cal. A.P. y localizadas en un rango altitudinal de 3400 a $3600 \mathrm{~m}$, se puede correlacionar con el trabajo de Lozano-García y Vázquez-Selem (2005). Los cambios de vegetación durante el Holoceno medio, fueron identificados por estos autores mediante registros de polen en una pequeña depresión localizada a 3860 m en el NW del Iztaccíhuatl. Ahí se registra el desarrollo de zacatonal alpino a inicios del Holoceno, pero el bosque de pino se desarrolla de manera importante por primera vez entre $\sim 7500$ y $\sim 6500$ años cal. A.P., es decir, poco antes de la caída de la pómez Ocre, y en coincidencia con la retirada de los glaciares de la fase Milpulco-2 en las partes altas del Iztaccíhuatl (Lozano-García y Vázquez-Selem, 2005). Con base en esto se puede proponer que las condiciones climáticas que se instalaron en laderas montañosas de la Sierra Nevada entre $\sim 7500$ y $\sim 6500$ cal. A.P. y que propiciaron la expansión del bosque de pino hasta altitudes de $\sim 3900 \mathrm{msnm}$, favorecieron a la vez la estabilización gradual de las laderas y el inicio del desarrollo del suelo en las barrancas de la zona estudiada (3400 - $3600 \mathrm{~m})$. Presumiblemente se trata de condiciones más húmedas y cálidas que las de la fase precedente (avance glacial Milpulco-2), y permitieron el desarrollo de una cubierta vegetal más densa, en particular bosque de pino (Pinus hartwegii) con un sotobosque de pastos amacollados como el que domina en la zona actualmente. Entre $\sim 6500$ y $~ 5000 \mathrm{cal}$. A.P., el bosque retrocedió de las zonas más altas de las montañas pero el zacatonal permaneció (Lozano-García y Vázquez-Selem, 2005), lo cual debió contribuir a la estabilidad geomórfica en la zona aquí estudiada, donde se observa desarrollo del suelo inmediatamente debajo de la Pómez Ocre (Figura 2).

De acuerdo con Lozano-García y Vázquez-Selem (2005), desde hace $\sim 3000$ años el bosque de pino en sitios cercanos al límite superior del bosque presenta condiciones similares a las actuales, con altos porcentajes de polen arbóreo. Probablemente estas condiciones explican que la pómez Pink, que 
manteó toda la zona hace $\sim 1100$ años cal. A.P., se preserve notablemente bien incluso en pendientes muy fuertes como las de las laderas de la barranca Pelagallinas (Figura 2). La mejor preservación de la pómez Pink en comparación con la Ocre sugiere que en el último tercio del Holoceno las condiciones bioclimáticas favorables a la estabilidad geomórfica se han acentuado en comparación con las del Holoceno medio, a altitudes alrededor de los $3500 \mathrm{msnm}$.

Otra información valiosa se relaciona con la muestra de carbón POP-02 procedente de una terraza lahárica en el interior de la barranca Huiloac (NE del volcán). La edad de 930 - 1170 años cal. A.P. (1105 \pm 40 años ${ }^{14} \mathrm{C}$ A.P.) sugiere que la terraza se originó durante las etapas finales de la última explosión pliniana del Popocatépetl, correspondiente a la pómez Pink (Siebe et al., 1996b, 1997). Considerando que: (a) la barranca está excavada en materiales piroclásticos de la erupción Pink, y (b) tiene un relleno lahárico de edad ${ }^{14} \mathrm{C}$ indistinguible de otras fechamientos asociados a la misma erupción, por lo que se propone que la formación de la barranca ocurrió de manera inmediata a la erupción.

La barranca de Huiloac es producto de la incisión de $\sim 30 \mathrm{~m}$ a través de flujos piroclásticos y pómez de caída Pink. Considerando que la edad del relleno lahárico (930 - 1170 años cal. A.P.) es muy cercana a los fechamientos asociados a la erupción Pink ( 1100 años cal. A.P.), debió transcurrir poco tiempo entre el final de la erupción, la excavación de la barranca y el depósito del relleno lahárico post-volcánico al interior de la barranca. La excavación del relleno lahárico y formación de la terraza debió ocurrir poco después del evento lahárico fechado, como ocurrió con los rellenos de 1997 y 2001 (Capra et al., 2004). En suma, esta interpretación sugiere que la barranca Huiloac y otras aledañas similares se formaron poco después del final de la última erupción pliniana, hace $\sim 1100$ años cal. A.P. También, es interesante notar que la terraza lahárica fechada representa el lahar más voluminoso en la barranca Huiloac desde hace $\sim 1100$ años cal. A.P.
Cabe mencionar que la edad mínima del relleno lahárico en la barranca Huiloac, determinada con base en la edad de los árboles es de $\sim 160$ años (árbol más viejo que crece en su superficie), mientras que la edad mínima de la incisión fluvial está dada por el árbol más viejo que crece al interior del corte excavado en dicho relleno (54 años en el caso mostrado en la Figura 6).

Los resultados generales de esta investigación apoyan la tesis de que las barrancas en laderas de volcanes activos, se forman muy pronto después de las fases eruptivas mayores - sobre todo cuando los depósitos piroclásticos sepultan las redes de drenaje previas y crean nuevas superficies geomórficas - y en lo sucesivo se transforman lentamente (Segerstrom, 1960, 1961; Richards, 1965; Inbar et al., 1994, 2001; Thouret, 1999; Németh y Cronin, 2007; Gran et al., 2011). Un caso bien documentado al respecto es el del Monte Pinatubo, Filipinas, donde se formaron barrancas de $\sim 35 \mathrm{~m}$ excavadas en flujos piroclásticos y terrazas laháricas dentro de dichas barrancas en el año siguiente a la erupción de junio de 1991 (Daag y Van Westen, 1996). En contraste, barrancas desconectadas del cono activo, y formadas en zonas donde los depósitos piroclásticos mantearon la topografía sin sepultarla, presentan mayor estabilidad geomórfica. Es el caso de las barrancas B1, B2 y B3, que fueron excavadas en depósitos Tutti-Frutti, entre $\sim 17000$ y $\sim 6000$ años cal. A.P., cuando aún prevalecían condiciones más frías y con menor cobertura forestal que las actuales y en los últimos $\sim 6000$ años cal. A.P. han presentado poca actividad en sus laderas y cauces incluso después de las erupciones plinianas ocurridas desde el Holoceno medio y hasta la etapa eruptiva actual del Popocatépetl.

Las edades mínimas de relieve y procesos geomorfológicos, se analizaron a partir de métodos dendrocronológicos estándar y conteo simple de anillos. Se puede decir que esta forma de evaluar la dinámica morfológica en terrenos volcánicos es de bajo costo y da excelentes resultados. Aunque la edad del arbolado en general solamente representa una edad mínima respecto a la formación de las barrancas, ofrece información valiosa sobre 
el momento en que se estabilizaron sus laderas, cabeceras y canal. Por ejemplo en el caso de La Venta (caso B3), la edad de los árboles que crecen en terrazas jóvenes, cercanas al fondo, permite estimar tasas de incisión en las últimas décadas. Por métodos dendrocronológicos también es posible reconstruir eventos laháricos asociados a lluvias torrenciales intra-eruptivas que no han dejado una huella evidente en la estratigrafía o en las geoformas, pero sí en el arbolado del fondo de las barrancas. Así lo ha demostrado el estudio de Bollschweiler et al. (2010) en la propia barranca de Huiloac, y el de Franco-Ramos et al. (2013) en barrancas del Volcán de Colima.

Finalmente, la tipología de barrancas propuesta para este estudio (Figura 8), resultó de la extrapolación de la información estratigráfica de campo y de los análisis de las muestras dendrocronológicas. Esta tipología y el mapa correspondiente permiten identificar barrancas (o sectores de ellas) muy activas, distinguiéndolas de aquellas que, aunque muestran apariencia morfológica joven, han permanecido estables durante décadas o incluso siglos. Esto puede ser de utilidad en la definición de las políticas de manejo de esta zona, que en parte corresponde a un área natural protegida conocida como Parque Nacional Izta-Popo.

\section{Agradecimientos}

Este trabajo fue apoyado por el proyecto DGAPA-PAPIIT clave IN105213 y IN109216. Un agradecimiento especial a la Dra. Lucia Capra por sus valiosas observaciones y comentarios del trabajo, así como los revisores que permanecieron anónimos.

\section{Referencias}

Arana-Salinas, L., Siebe, C., Macías J.L., 2010, Dynamics of the $c a .4965 \mathrm{yr}{ }^{14} \mathrm{C} \mathrm{BP}$ "Ochre
Pumice" Plinian eruption of Popocatépetl volcano, México: Journal of Volcanology and Geothermal Research, 192, 212-231.

Bollschweiler, M., Stoffel, M., Vázquez-Selem, L., Palacios, D., 2010, Tree-ring reconstruction of past lahar activity at Popocatepetl volcano, Mexico: The Holocene, 20, 265-274.

Capra, L., Poblete, M.A., Alvarado, R., 2004, The 1997 and 2001 lahars of Popocatépetl volcano (Central Mexico): textural and sedimentological constraints on their origin and hazards: Journal of Volcanology and Geothermal Research, 131, 351-369.

Castillo, M., Muñoz-Salinas, E., Arce, J.L., 2015, Evaluación del sistema erosivo fluvial en el volcán Popocatépetl (México) mediante análisis morfométricos: Boletín de la Sociedad Geológica Mexicana, 67, 167-183.

Daag, A., Van Westen, C.J., 1996, Cartographic modelling of erosion in pyroclastic flow deposits of Mount Pinatubo, Philippines: ITC Journal, 2, 110-124.

Davidson, J., De Silva, S., 2000, Composite volcanoes, en Sigurdsson, H. (ed.), Encyclopedia of volcanoes: San Diego \& Londres, Academic Press, USA. 663-681.

Franco-Ramos, O., Stoffel, M., Vázquez-Selem, L., Capra, L., 2013, Spatio-temporal reconstruction of lahars on the southern slopes of Colima volcano, Mexico - A dendrogeomorphic approach: Journal of Volcanology and Geothermal Research, 267, 30-38.

Fritts, H.C., 1976, Tree rings and climate: Nueva York, Academic Press, 567 pp.

González-Huesca, A.E., 2000, Estudios de detalle estratigráfico y sedimentológico del Lahar de San Nicolás en el flanco noreste del volcán Popocatépetl: México: Facultad de Ingeniería, UNAM, tesis de licenciatura, 110 pp.

Gran, K.B., Montgomery, D.R., Halbur, J.C., 2011, Long-term elevated post-eruption sedimentation at Mount Pinatubo, 
Philippines: Geology, 39, 367-370.

Inbar, M., Lugo, J., Villers, L., 1994, The geomorphological evolution of the Paricutin cone and lava flows, Mexico, 1943-1990: Geomorphology, 9, 57-76.

Inbar, M., Reyes, A., Graniel, J., 2001, Morphological changes and erosion processes following the 1982 eruption of El Chichón volcano, Chiapas, Mexico: Géomorphologie: relief, processus, environnement, 3, 175-184.

Koch, J., 2009, Improving age estimates for late Holocene glacial landforms using dendrochronology - some examples from Garibaldi Provincial Park, British Columbia: Quaternary Geochronology, 4, 130-139.

Lozano-García, S., Vázquez-Selem, L., 2005, A high-elevation Holocene pollen record from Iztaccíhuatl volcano, central Mexico: The Holocene, 15, 329-338.

Macías, J.L., 2005, Geología e historia eruptiva de algunos de los grandes volcanes activos de México: Boletín de la Sociedad Geológica Mexicana, 3, 379-424.

Manville, V., Németh, K., Kano, K., 2009, Source to sink: A review of three decades of progress in the understanding of volcaniclastic processes, deposits, and hazards: Sedimentary Geology, 220, 136-161.

Mooser, F., 1967, Tefracronología de la Cuenca de México para los últimos treinta mil años: Bol. INAH, 30, 12-15.

Muñoz-Jiménez, J., Rangel-Rios K., García Romero, A., 2005, Plant colonization of recent lahar Popocatepetl volcano, Mexico: Physical Geography, 26, 199-215.

Németh, K., Cronin, S.J., 2007, Syn- and posteruptive erosion, gully formation, and morphological evolution of a tephra ring in tropical climate erupted in 1913 in West Ambrym, Vanuatu: Geomorphology, 86, 115-130.

Nixon, G.T., 1989, The Geology of Iztaccíhuatl volcano and adjacent areas of the Sierra
Nevada and Valley of Mexico: Geological Society of America Special Paper, 219, 1-59. Panfil, M.S., Gardner, T.W., Hirth, K.G.,1999, Late Holocene stratigraphy of the Tetimpa archaeological sites, northeast flank of Popocatépetl volcano, central Mexico: Geological Society of America Bulletin, 111, 204-218.

Pierson, C.T., Major, J.J., 2014, Hydrogeomorphic effects of explosive volcanic eruptions on drainage basins: Annual Review of Earth and Planetary Sciences, 42, 469-507.

Pierson, T., 2007, Dating young geomorphic surfaces using age of colonizing Douglas fir in southwestern Washington and northwestern Oregon, USA: Earth Surface Processes and Landforms, 32, 811-831.

Reimer, P.J., Bard, E., Bayliss, A., Beck, J.W., Blackwell, P.G., Bronk Ramsey, C., Buck, C.E., Cheng, H., Edwards, R.L., Friedrich, M., Grootes, P.M., Guilderson, T.P., Haflidason, H., Hajdas, I., Hatté, G., Heaton, T.J., Hoffmann, D.L., Hogg, A. G., Hughen, K.A., Kaiser, K.F., Kromer, B., Manning, S.W., Niu, M., Reimer, R. W., Richards, D.A., Scott, E.M., Southon, J.R., Staff, R.A., Turney, C.S.M., van der Plicht, J., 2013, IntCal13 and Marine13 Radiocarbon Age Calibration Curves 0-50000 Years cal BP: Radiocarbon, 55, 1869-1887.

Richards, A., 1965, Geology of the Islas Revillagigedo, 3. Effects of erosion on Isla San Benedicto 1952-61 following the birth of Volcan Bárcena: Bulletin of Volcanology, 28, 381-403.

Rinntech, 2014, TSAP-WinTM, Time Series Analysis and Presentation for Dedrochronology and Related Applications, disponible en http://www.rinntech.com, accesado en marzo 2014.

Robin, C., 1984, Volcan popocatepetl (Mexico): Structure, petrology and risks: Bulletin of Volcanology, 47, 1-23. 
Robin, C., Boudal, C., 1987, A gigantic bezymianny-type event at the beginning of modern volcan Popocatepetl: Journal of Volcanology and Geothermal Research, 31, 115-130.

Schaaf, P., Stimac, J., Siebe, C. y Macías, J.L., 2005, Geochemical evidence for mantle origin and crustal processes in volcanic rocks from Popocatépetl and surrounding monogenetic volcanoes, Central México: Journal of Petrology, 46, 1243-1282.

Segerstrom K., 1950, Erosion studies at Paricutin, state of Michoacan, Mexico: United States Geological Survey Bulletin, 965-A, 164 pp.

Segerstrom K., 1960, Erosion and related phenomena at Paricutin in 1957: United States Geological Survey Bulletin, 1104-A, $1-18$.

Segerstrom K., 1961, Decelaration of erosion at Paricutin, Mexico: United States Geological Survey Professional Paper, 424-D, D225-D227.

Siebe, C., Abrams, M., Macías, J.L., 1996a, Derrumbes gigantes, depósitos de avalancha de escombros y edad del actual cono del volcán Popocatépetl, en Volcán Popocatépetl. Estudios realizados durante la crisis de 19941995: Distrito Federal, Sistema Nacional de Protección Civil, Centro Nacional de Prevención de Desastres, Universidad Nacional Autónoma de México, 195-220.

Siebe, C., Abrams, M., Macías, J.L., Obenholzner, J., 1996b, Repeated volcanic disasters in Prehispanic time at Popocatepetl, central Mexico: past key to the future?: Geology, 24, 399-402.

Siebe, C., Macías, J.L., Abrams, M; Obenholzner, J., 1996c, La destrucción de Cacaxtla y Cholula: un suceso en la historia eruptiva del Popocatépetl: Ciencias, 41, 36-45.

Siebe, C., Macías, J.L., Abrams, M., Rodríguez, S., Castro, R., 1997, Catastrophic Prehistoric eruptions at Popocatepetl and Quaternary explosive volcanism in the Serdan-Oriental Basin, East-Central Mexico (fieltrip guidebook), en International Association of Volcanology and Chemistry of the Earth's Interior (IAVCEI) General Assembly: Puerto Vallarta, Jalisco, México, IAVCEI, 19-24.

Sosa-Ceballos, G., Gardner,J.E., Siebe, C., Macías, J.L., 2012, A caldera-forming eruption $\sim 14100{ }^{14} \mathrm{C}$ yr BP at Popocatépetl volcano, México: Insights from eruption dynamics and magma mixing: Journal of Volcanology and Geothermal Research, 213-214, 27-40.

Sosa-Ceballos, G., Macías, J.L., García-Tenorio, F., Layer, P., Schaaf, P., Solís-Pichardo, G., Arce, J.L., 2015, El Ventorrillo, a paleostructure of Popocatépetl volcano: insights from geochronology and geochemistry: Bulletin of Volcanology, 77, 2-20.

Stoffel, M., Bollschweiler, M., 2008, Tree-ring analysis in natural hazards research- an overview: Natural Hazards and Earth System Sciences, 8, 187-202.

Stoffel, M., Corona, C., 2014, Dendroecological dating of geomorphic disturbance in trees: Tree-Ring Research, 70, 3-20.

Stokes, M., Smiley, T., 1996, An Introduction to Tree-Ring Dating: Tucson, The University of Arizona Press, 73 pp.

Stuiver, M., Reimer, P.J., 1993, Extended ${ }^{14} \mathrm{C}$ data base and revised CALIB radiocarbon calibration program: Radiocarbon, 35, 215-230.

Thouret, J.C., 1999, Volcanic geomorphology - an overview: Earth-Science Reviews, 47, 95-131.

Villalba, R., 2000, Métodos en dendrogeomorfología y su potencial uso en América del sur, en Roig, F.A. (comp.), Dendrogeomorfología en América Latina: Mendoza, Argentina, EDIUVG, 103-134.

Villanueva, J., Cerano, J., Constante, V., Montes, M.C.L.E., Vázquez, L., 2009, Muestreo Dendrocronológico: colecta, preparación y procesamiento de núcleos de crecimiento y secciones transversales: Gómez Palacio, Dgo., INIFAP, CENID-RASPA, Folleto Técnico, 13, 49 pp. 
Villanueva Díaz, J., Cerano Paredes, J., Stahle, D.W., Constante García, V., Vázquez Selem, L., Estrada Ávalos, J., Benavides Solorio, J.D., 2010, Árboles longevos de México: Revista Mexicana de Ciencias Forestales, 1, 7-29.. 